\title{
Surgical morbidity and mortality of pediatric brain tumors: a single center audit
}

\author{
F. W. Neervoort • W. J. R. Van Ouwerkerk • \\ H. Folkersma • G. J. L. Kaspers • W. P. Vandertop
}

Received: 10 December 2009/Accepted: 20 January 2010/Published online: 5 March 2010

(C) The Author(s) 2010. This article is published with open access at Springerlink.com

\begin{abstract}
Objectives The primary aim of this study is to perform an internal quality control of pediatric brain tumor surgery in the neurosurgical department of the VU University Medical Center Amsterdam (The Netherlands). Secondly, this study aims to contribute to the accumulating data concerning outcome in pediatric neurosurgery, in order to establish institutional practice benchmarks.

Methods We report the surgical mortality and morbidity of 121 patients ( $0-18$ years) surgically treated for a brain tumor from January 1999 to August 2007. Patients, in whom only a brain tumor biopsy was performed, were excluded.

Results Mean age at first surgery was 8.2 years. Of the 121 patients, 14 had a second surgery, and two underwent a third surgery (for a total of 137 operations). Of all 121 primary surgeries, $66 \%$ were total resections, $26 \%$ subtotal resections, and $8 \%$ partial resections. The overall surgical morbidity rate in this study was $69 \%$ after first surgery, $50 \%$ after second surgery, and one out of two after third surgery.

Conclusion These overall morbidity rates are comparable to other published mixed case series. The surgical mortality rate was $0.8 \%$; this is comparable to the lowest rates reported

F. W. Neervoort $\cdot$ W. J. R. Van Ouwerkerk $\cdot$ H. Folkersma $\cdot$

W. P. Vandertop

Neurosurgical Center Amsterdam, VU University Medical Center,

Amsterdam, The Netherlands

\section{G. J. L. Kaspers}

Pediatric Oncology/Hematology, VU University Medical Center, Amsterdam, The Netherlands

\section{W. P. Vandertop $(\triangle)$}

Department of Neurosurgery, 2F-020,

VU University Medical Center,

P.O. Box 7057, 1007 MB Amsterdam, The Netherlands

e-mail: wp.vandertop@vumc.nl
\end{abstract}

for high-volume neurosurgical centers. We encourage other neurosurgical centers to collect, analyze, and publish their data. These data can then serve as a basis for comparison with other pediatric neurosurgical centers and will eventually lead to an improvement of pediatric neurosurgical practice and patient care.

Keywords Brain neoplasms · Craniotomy · Mortality · Complication · Postoperative $\cdot$ Benchmarking . Quality assurance $\cdot$ Health Care $\cdot$ Clinical audit

\section{Objective}

Nowadays, quality control of medical care is becoming increasingly more important. In hospitals, departments are required to meet certain quality standards, and internal auditing is an instrument that can be used to obtain treatment outcome data. Transparent publication of these performance data is also expected by external stakeholders. For surgical specialties, these data do not only give an indication of the quality of care and accurate information about operative risks but also allow for the analysis of factors to improve patient care and for comparison of the results with those of other surgeons and institutions [2]. Outcome indicators of patient care are hardly available in pediatric neurosurgery, particularly in the Netherlands.

Brain tumors are the second most common malignancy to occur during childhood. Surgical resection, as a first step in the multidisciplinary treatment, remains the mainstay of treatment $[5,10,17,20,22]$. Outcome analysis for this kind of surgical procedure is complex, but relatively easy to define parameters are postoperative mortality and morbidity, of which some data have now been published. Usually, these data pertain to single tumor entities, such as medulloblas- 
tomas, brain stem tumors, or ependymomas. However, outcome data on mixed tumor case series have not been reported frequently, whereas for most centers treating children with brain tumors, these data may be more pertinent to compare to than the outcome data on single tumor entities, which are often derived from renowned, large pediatric neurosurgical centers, which are not readily accessible for most patients around the world [1, 3, 19, 22].

The aim of this study was to perform an internal quality control of the pediatric neurosurgical department of the VU University medical center (VUmc) Amsterdam (The Netherlands), a tertiary referral center for children with brain tumors, and to relate the data to published international outcomes. This way, we hope to contribute to the outcome data concerning pediatric neurosurgery and to establish institutional practice benchmarks for smaller, less specialized centers.

\section{Methods}

Between January 1999 and August 2007, 149 children were surgically treated for an intracranial neoplasm at the VUmc (Amsterdam, the Netherlands). All patients were younger than 18 years at the time of first surgery. Patients, in whom only a brain tumor biopsy $(n=28)$ was performed, were excluded. In the remaining 121 children, 137 craniotomies were performed. All data were collected by retrospectively reviewing patient medical records. In those cases where the medical records were incomplete, additional information was collected from the Medical Administration's Office or from local hospitals. All patients were examined in detail, pre- and postoperatively, by pediatricians, pediatric neurologists, and neurosurgeons, and all patients had previously undergone a complete investigative work-up with computed tomography (CT), magnetic resonance (MR) scan, or both.

Surgical techniques included image-guided microsurgery, ultrasonic aspiration, ultrasound tumor localization, and cortical mapping, with the individual cases dictating the techniques required. Each surgical procedure was attended by one of the senior pediatric neurosurgeons. The objectives of surgery were maximal possible resection of the tumor with optimal neurological outcome. The radicality of the resection was determined by postoperative CT or MR scans, or in lack thereof, estimated by analyzing the surgeon's estimate as described in surgical reports. The extent of tumor resection for each patient was graded as follows: complete resection (no residual tumor on postoperative neuroimaging or highly probable surgeon's estimation), subtotal (more than $80 \%$ resection), and partial (less than $80 \%$ resection). The cause for partial removal was retrieved from the operative reports and was classified as either due to the tumor's pathology/anatomy, technical reasons, or a combination of these.
Each type of tumor was graded and specified according to the 2007 WHO classification [11]. The tumor locations were divided into eight categories: supratentorial/right or left hemisphere/ventricle, cerebellum, brain stem, fourth ventricle, sellar/suprasellar/third ventricle, thalamus/basal nuclei, cerebellopontine angle, and pineal gland.

The histopathological diagnosis and age determined which adjuvant therapies, such as radiotherapy and chemotherapy, were given. Residual or recurrent tumors during follow-up were resected (second or a third craniotomy) if they showed radiological progression or when they caused symptoms. Operative morbidity, determined after first, second, and third surgery, was defined as any complication leading to symptoms or to unpredicted intervention within 30 days postoperatively, surgical mortality as death within 30 days postoperatively. Complications were classified into seven groups: none, neurological, endocrinological, infectious, cerebrospinal fluid (CSF) disturbances, postoperative hematoma, and other. These complications were dichotomized into short-term (resolved when the patient was discharged) and long-term (causing the patient's death or permanent disability at time of discharge). We specified the endocrinological complications for different tumor locations. In cases of CSF disturbances, shunt dependency was classified as a long-term complication. Causes of postoperative hematoma and their consequences were analyzed by reviewing the surgical reports. For all deceased patients, the cause of death was established.

Statistical analysis Patients who had undergone surgery for at least 6 months before the closure of the study were included for survival analysis. Since WHO classification and the extent of surgical resection are both associated with survival $[14,22]$, we analyzed our survival data using a Log Rank trend test. Separate Kaplan-Meir curves were made to visualize survival functions. All analyses were conducted with statistical software (SPSS 15.0).

\section{Literature review}

A literature search of the National Library of Medicine database (Pubmed; 1960-the present) was conducted in May 2009, using subject headings (MeSH) and keywords and limited to human studies. The terms "Brain Neoplasms," "Pediatrics," "Outcome Assessment (Health Care)," "Mortality," "Morbidity," "Neurosurgery," and "Postoperative Complications" were used. Publications written in a language other than English, Dutch, French, or German were excluded, as were abstracts, editorials, letters, comments, or publications before 1960 . The abstracts were reviewed, and articles unrelated to the specific topic were excluded. Duplicate references, as well as redundant publications, were 
Age at first surgery

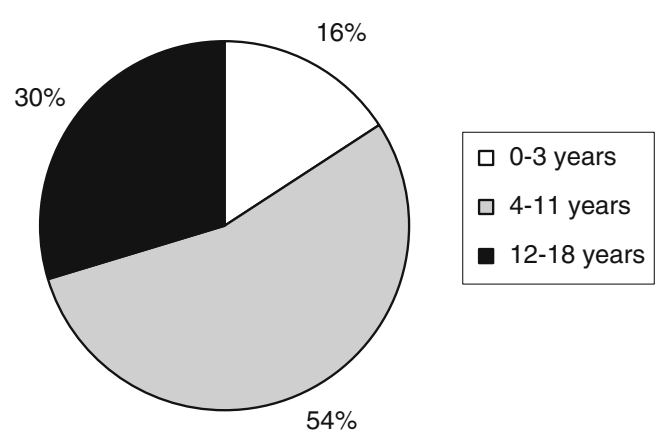

Fig. 1 Age distribution at presentation of children with a brain tumor $(N=121 ;$ mean age $=8.2$ years $)$

discarded. Using these research criteria, all studies considered eligible were retrieved, and the final selection was based on the full article. To identify additional eligible studies, the reference lists were also screened for journal articles. An analysis of the published studies concerning surgical morbidity and mortality for pediatric brain tumors was performed. The data extraction included the following parameters: (1) year of publication and author, (2) number of reported patients, (3) reported surgical morbidity and mortality, (4) types of surgery studied, (5) histopathological types and location of tumors diagnosed, (6) extent of resection, and (7) duration of follow-up.
Neurological complications

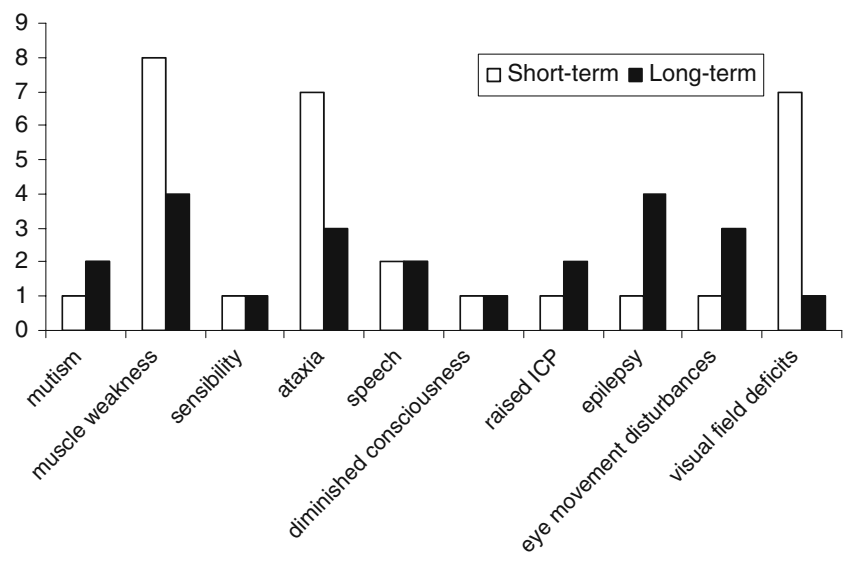

Fig. 2 Specification and number of neurological complications after first surgery. ICP intracranial pressure

\section{Results}

Patient characteristics

There were 70 boys and 51 girls, for a male-to-female ratio of 1.4:1. The mean age at the time of first surgery was 8.2 years (range $0-17.9$; Fig. 1). All 121 patients underwent primary surgery, 14 patients had a second surgery, and two patients underwent a third surgery (for a total of 137
Table 1 Summary of 121 cases with respect to diagnosis, extent of surgery, and WHO classification

\begin{tabular}{|c|c|c|c|c|c|}
\hline Histopathological diagnosis & $\begin{array}{l}\text { Total } \\
\text { resection }\end{array}$ & $\begin{array}{l}\text { Subtotal } \\
\text { resection }\end{array}$ & $\begin{array}{l}\text { Partial } \\
\text { resection }\end{array}$ & WHO & $N$ \\
\hline \multirow[t]{4}{*}{ Astrocytic tumors $(41 \%)$} & \multirow[t]{4}{*}{26} & \multirow[t]{4}{*}{14} & \multirow[t]{4}{*}{9} & I & 34 \\
\hline & & & & II & 6 \\
\hline & & & & III & 2 \\
\hline & & & & IV & 7 \\
\hline Embryonal tumors $(20 \%)$ & 18 & 5 & 1 & IV & 24 \\
\hline Tumors of the sellar region $(9 \%)$ & 9 & 2 & - & I & 11 \\
\hline \multirow[t]{2}{*}{ Ependymal cell tumors $(7 \%)$} & \multirow[t]{2}{*}{7} & \multirow[t]{2}{*}{2} & \multirow[t]{2}{*}{-} & II & 7 \\
\hline & & & & III & 2 \\
\hline \multirow[t]{2}{*}{ Oligodendroglial tumors $(5 \%)$} & \multirow[t]{2}{*}{1} & \multirow[t]{2}{*}{5} & \multirow[t]{2}{*}{-} & II & 4 \\
\hline & & & & III & 2 \\
\hline Nonmeningothelial tumors of the meninges ( $5 \%)$ & 5 & 1 & - & I & 6 \\
\hline \multirow[t]{2}{*}{ Choroid plexus tumors $(3 \%)$} & \multirow[t]{2}{*}{3} & \multirow[t]{2}{*}{1} & \multirow[t]{2}{*}{-} & I & 3 \\
\hline & & & & II & 1 \\
\hline Neuronal and mixed neuronal-glial tumors $(2 \%)$ & 3 & - & - & I & 3 \\
\hline Cysts and tumor-like lesions (2\%) & 3 & - & - & I & 3 \\
\hline \multirow[t]{2}{*}{ Germ cell tumors $(2 \%)$} & \multirow[t]{2}{*}{2} & \multirow[t]{2}{*}{-} & \multirow[t]{2}{*}{-} & II & 1 \\
\hline & & & & III & 1 \\
\hline Pineal tumors $(1 \%)$ & - & 1 & - & IV & 1 \\
\hline Metastatic tumors (1\%) & 1 & - & - & IV & 1 \\
\hline Tumors of the meninges $(1 \%)$ & 1 & - & - & I & 1 \\
\hline \multirow[t]{2}{*}{ Unclassified tumor $(1 \%)$} & 1 & - & - & & 1 \\
\hline & $N=80$ & $N=31$ & $N=10$ & & $N=121$ \\
\hline
\end{tabular}


Fig. 3 Specification, number, and tumor location of short-term endocrinological complications after first surgery

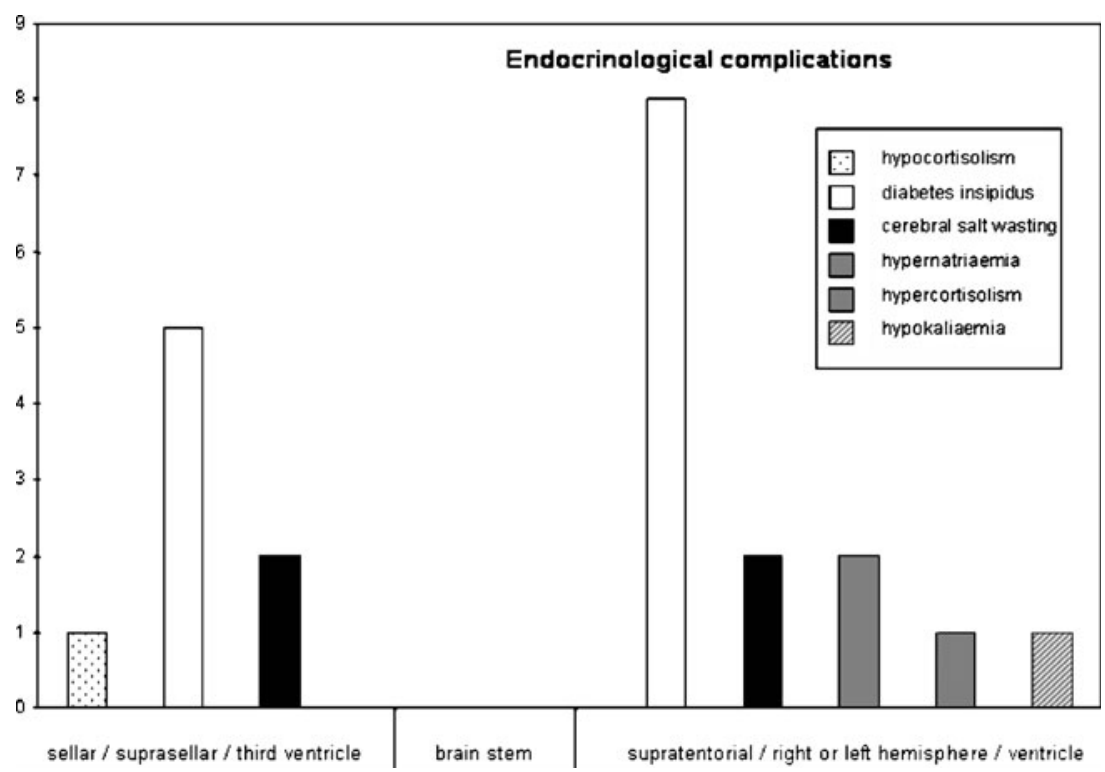

operations). Of all 121 primary surgical procedures, 80 $(66 \%)$ were total resections, 31 (26\%) subtotal resections, and ten (8\%) partial resections. Reasons for partial removal of tumors were nine times the unfavorable pathology/ anatomy of the tumor (e.g., brain stem invasion or severe blood loss) and once for technical reasons (deficient neuronavigation because of patient's dental brackets). In general, reasons for subtotal removal were unfavorable anatomy/pathology of the tumor. A summary of the 121 cases with regard to the histopathological diagnosis, extent of resection, and WHO classification is given in Table 1. The tumor locations were as follows: supratentorial/right or left hemisphere/ventricle, 47; cerebellum, 21; brain stem, 18; fourth ventricle, 16; sellar/suprasellar/third ventricle, ten; thalamus/basal nuclei, seven; cerebellopontine angle, one; and pineal gland, one.

Operative morbidity after first surgery

After first surgery in 121 patients, 38/121 patients (31\%) had an uneventful postoperative period. In the remaining 83 patients $(69 \%)$, the distribution of complications was as follows: 53/121 (44\%) neurological complications, 27/121 (22\%) endocrinological disturbances, 25/121 (21\%) infectious complications, 21/121 (17\%) CSF disturbances, 5/121 (4\%) postoperative hematomas, and 21/121 (17\%) other complications. Multiple complications could occur in one single patient.
Fig. 4 Specification, number, and tumor location of long-term endocrinological complications after first surgery

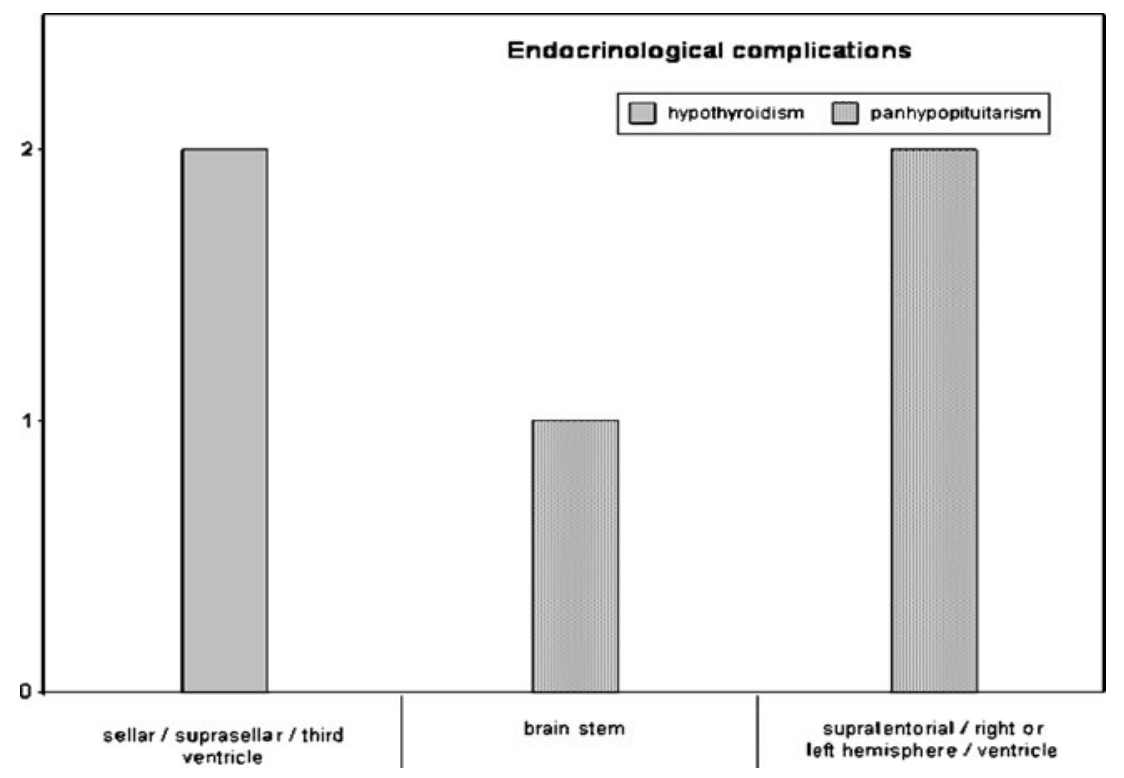


Of the 53 neurological complications, $23(19 \%)$ were still present at discharge and classified as long-term. In Fig. 2, all neurological complications are specified.

Operative endocrinological complications included diabetes insipidus, panhypopituitarism, hypothyroidism, hypoand hypercortisolism, hypokalemia, hypernatremia, and cerebral salt wasting. Except for patients with panhypopituitarism and hypothyroidism, all endocrinological complications were short-term. In cases of panhypopituitarism and hypothyroidism, patients still have hormone replacement therapy, and these complications are therefore classified as long-term. The endocrinological complications were seen in three tumor locations: sellar/suprasellar/third ventricle, brain stem, and supratentorial/right or left hemisphere/ ventricle (Figs. 3 and 4).

The surgical infectious complications consisted of meningitis, urinary tract infections, and wound infections and were all short-term. One patient ( 3 years old) with a supratentorial glioblastoma multiforme developed a bone flap infection, which was removed. Shortly after this was resolved, the neurological status worsened, and the patient died 2 months later due to rapid tumor progression and leptomeningeal metastases before discharge was possible.

Of all 21 CSF disturbances, only four (19\%) patients turned out to be shunt-dependent; other CSF disturbances were CSF leaks or postoperative pseudomeningoceles, which could be resolved by temporary drainage or compression bandage.

In five cases, a postoperative hematoma occurred. One patient had a postoperatively discovered epidural hematoma caused by a temporal bone fracture due to using the Mayfield clamp. This patient needed a second emergency surgery to remove the hematoma and made an uneventful recovery. In another patient, the postoperative hematoma was located in the brain stem and caused brain stem dysfunction. After referral to a rehabilitation center, the patient's condition improved considerably (able to walk independently, talking fluently). In the other three cases, a hematoma was found on postoperative imaging and was treated by drainage.

\section{Operative morbidity after second surgery}

After second surgery in 14 patients, 7/14 (50\%) patients had an uneventful postoperative period. In the other seven patients $(50 \%)$, the distribution of complications was as follows: 11/14 (79\%) neurological complications, 1/14 (7\%) endocrinological disturbance, 1/14 (7\%) CSF disturbance, and $1 / 14(7 \%)$ other complication. Again, multiple complications could occur in one single patient.

In Fig. 5, the neurological complications, which were all long-term, are specified.

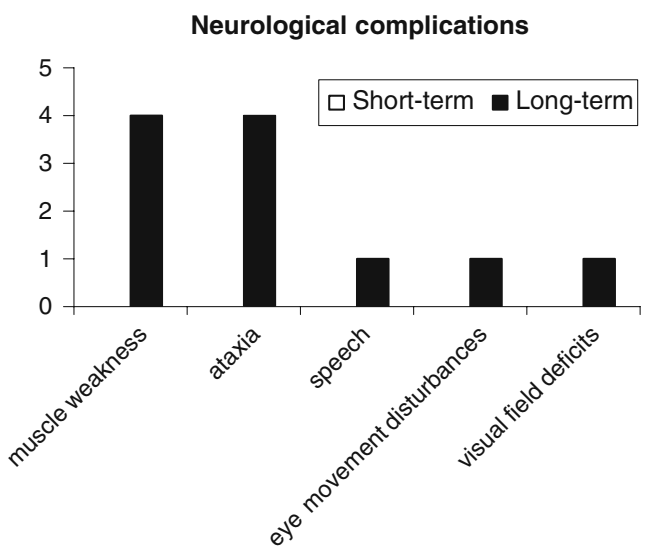

Fig. 5 Specification and number of neurological complications after second surgery

The sole endocrinological complication was a short-term diabetes insipidus. The patient with a CSF disturbance became shunt-dependent. One patient developed a persistent headache, which was classified as "other complication."

A summary of the postoperative complications after first and second surgery is shown in Table 2 . The distribution of complications among the patients is presented in Table 3 .

Operative morbidity after third surgery

There were two tertiary operations. The first patient (6 years old) had a malignant choroid plexus papilloma. After the third craniotomy for recurrent disease, the patient was discharged without any postoperative neurological deficits. At follow-up, a slight hemiparesis on the right side and periods of epileptic insults were observed. The hemiparesis worsened, and a severe dyspraxia is present. The second patient (6 years old) had an embryonal tumor. A postoperative partial epileptic seizure occurred, after which, a long-term speech disturbance and visual deficits on the right side remained. During follow-up, the tumor recurred despite a long period of treatment with chemotherapy. There were no curable options, and 2 months after following the GEMOX regimen (gemcitabine plus oxaliplatin combination), the patient died.

In short, the postoperative morbidity after third surgery amounted to one out of two patients; all were neurological complications.

\section{Operative mortality}

One patient (4 days old) died within 30 days after first surgery, resulting in a surgical mortality of $0.8 \%$. This patient was diagnosed with an astrocytoma WHO grade IV. During surgery, because of the size of the tumor, the brain collapsed, despite careful retraction, and although blood loss had not been severe, suddenly cardiac arrest occurred. 
Table 2 Summary of complications after first and second surgery

\begin{tabular}{lcccc}
\hline $\begin{array}{l}\text { Type of } \\
\text { complication }\end{array}$ & $\begin{array}{l}\text { Complications after first } \\
\text { surgery }(N \text { patients }=121)\end{array}$ & Percent & $\begin{array}{l}\text { Complications after second } \\
\text { surgery }(N \text { patients }=14)\end{array}$ & Percent \\
\hline None & 38 & 31 & 7 & 50 \\
Neurological & 53 & 44 & 11 & 79 \\
Endocrinological & 27 & 22 & 1 & 7 \\
Infectious & 25 & 21 & 0 & 0 \\
CSF disturbances & 21 & 17 & 0 & 7 \\
Hematoma & 5 & 4 & 1 & 7 \\
Other & 21 & 17 & & 0 \\
\hline
\end{tabular}

Resuscitation was unsuccessful. The cause of death was defined as central deregulation.

\section{Survival}

At the closure of the study, 23 (19\%) of the 121 patients had died: 21 patients due to tumor progression, one perioperatively, and one of a combined viral pneumonia ( $\mathrm{H}$. influenza type B and adenovirus) and ARDS (Table 4). The total cumulative survival is seen in Fig. 6.

The results from the Log Rank trend test showed that WHO classification and grade of tumor resection were significantly related to survival $(p<0.001 ; p=0.016$; Figs. 7 and 8$)$.

\section{Literature review}

The literature search resulted in ten articles concerning operative mortality after surgery of pediatric brain tumors. These data, including those of the current study, are summarized in Table 5.

\section{Discussion}

Previous reports on morbidity and mortality rates after craniotomies for brain tumors in children have (1) been limited to studying single entity tumors such as pilocytic astrocytomas, craniopharyngiomas, medulloblastomas, or brainstem tumors; (2) excluded patients undergoing repeat

Table 3 Number of complications per patient after first and second surgery

\begin{tabular}{lcc}
\hline $\begin{array}{l}\text { Number of } \\
\text { complications }\end{array}$ & $\begin{array}{l}N \text { (patients) } \\
\text { after first surgery }\end{array}$ & $\begin{array}{l}N \text { (patients) after } \\
\text { second surgery }\end{array}$ \\
\hline 0 & 38 & 7 \\
1 & 41 & 4 \\
2 & 23 & 1 \\
3 & 13 & 1 \\
4 & 4 & 0 \\
5 & 2 & 1 \\
\hline
\end{tabular}

surgery; and (3) included large numbers of patients from renowned, large, high-volume, pediatric neurosurgical centers [7-9, 12, 16, 18]. The current study concerns the surgical morbidity and mortality rates for all pediatric brain tumor patients combined and treated in one tertiary referral center between 1999 and 2007. The results are discussed in the light of the present literature.

\section{Quality assessment}

Outcome indicators of patient care in pediatric neurosurgery are hardly available, and a review of the literature shows remarkable differences in the reported results. Comparing the outcome data of different studies is difficult because of the heterogeneity of criteria used when selecting the type of surgery for each patient, when evaluating the extent of resection, or when defining surgical complications and their severity [4]. The reported morbidity and mortality rates for single tumor entities from large, high-volume centers are not necessarily representative for all those patients treated worldwide in less specialized, low-volume centers, by specialists with far less extensive experience. In addition, patients and their parents, and even our external stakeholders, are increasingly demanding their right to be informed about the actual morbidity and mortality rates obtained in the institution actually providing the care. To meet this demand, it is necessary for all care providers to audit their own results on a regular basis and to compare these with reported figures from comparable institutions. With this information, they can establish a prognosis not only in terms of survival and outcome but also in terms of treatment-related morbidity and mortality. This provides clinicians, parents, and policy makers with more accurate and reliable information upon which decisions can be based [2].

In several fields in surgery, it is well recognized that so-called high-volume hospitals and high-volume surgeons lead to lower mortality and morbidity rates and a better outcome for the patients $[6,19]$. It is therefore paramount for smaller centers to not only compare their results with similar institutions but also with the results obtained in these large centers. The VUmc has a pediatric neurosurgery 
Table 4 Summary of 23 deceased patients regarding gender, age, year of surgery, diagnosis, and cause of death

\begin{tabular}{|c|c|c|c|c|c|}
\hline Sex & Age (years) ${ }^{\mathrm{a}}$ & Year of surgery & Diagnosis & Observation time (months) ${ }^{\mathrm{b}}$ & Cause of death \\
\hline $\mathrm{F}$ & 8.9 & 2000 & Astrocytic tumor (WHO 1) & 21 & Tumor progression \\
\hline $\mathrm{F}$ & 2.8 & 2000 & Astrocytic tumor (WHO III) & 17 & Tumor progression \\
\hline $\mathrm{F}$ & 13.5 & 2004 & Astrocytic tumor (WHO III) & 17 & Tumor progression \\
\hline M & 7.6 & 2005 & Astrocytic tumor (WHO IV) & 2 & Tumor progression \\
\hline M & 4.3 & 2002 & Astrocytic tumor (WHO IV) & 10 & Tumor progression \\
\hline $\mathrm{F}$ & 0.9 & 1999 & Astrocytic tumor (WHO IV) & 5 & Tumor progression \\
\hline $\mathrm{F}$ & 8.9 & 2003 & Astrocytic tumor (WHO IV) & 12 & Tumor progression \\
\hline $\mathrm{F}$ & 4.0 & 2000 & Astrocytic tumor (WHO IV) & 7 & Tumor progression \\
\hline M & 3.7 & 2006 & Astrocytic tumor (WHO IV) & 2 & Tumor progression \\
\hline $\mathrm{F}$ & 14 & 2001 & Astrocytic tumor (WHO IV) & 23 & Tumor progression \\
\hline $\mathrm{F}$ & 0.0 & 2004 & Astrocytic tumor (WHO IV) & - & $\begin{array}{l}\text { Collapsed brain, central } \\
\text { deregulation, cardiac arrest }\end{array}$ \\
\hline M & 11.0 & 2000 & Oligodendroglial tumor (WHO II) & 11 & Tumor progression \\
\hline $\mathrm{F}$ & 13.1 & 2003 & Oligodendroglial tumor (WHO III) & 9 & Tumor progression \\
\hline M & 1.6 & 2002 & Ependymal cell tumor (WHO II) & 16 & Tumor progression \\
\hline M & 3.5 & 1999 & Ependymal cell tumor (WHO II) & 19 & Tumor progression \\
\hline $\mathrm{F}$ & 2.7 & 1999 & Ependymal cell tumor (WHO II) & 19 & Tumor progression \\
\hline M & 0.5 & 1999 & Pineal parenchyma tumor & 17 & Tumor progression \\
\hline M & 13.5 & 2004 & Embryonal tumor (WHO IV) & 8 & Tumor progression \\
\hline M & 2.0 & 2002 & Embryonal tumor (WHO IV) & 3 & Tumor progression \\
\hline $\mathrm{F}$ & 2.6 & 2004 & Embryonal tumor (WHO IV) & 2 & Tumor progression \\
\hline M & 10.8 & 2000 & Embryonal tumor (WHO IV) & 18 & Tumor progression \\
\hline M & 2.0 & 2003 & Embryonal tumor (WHO IV) & 2 & $\begin{array}{l}\text { Combined viral pneumonia } \\
\text { and ARDS }\end{array}$ \\
\hline $\mathrm{F}$ & 9.3 & 1999 & Embryonal tumor (WHO IV) & 8 & Tumor progression \\
\hline
\end{tabular}

ICP intracranial pressure, $C N S$ central nervous system, ARDS acute respiratory distress syndrome

${ }^{\text {a }}$ At time of tumor resection

${ }^{\mathrm{b}}$ Time between tumor surgery and death

unit that serves as one of the eight tertiary referral centers in The Netherlands (total population 16,645,313, of which, 1,427,297 (17.6\%) are 0-14 years) with subsequently a fairly modest volume of pediatric brain tumor patients.

\section{Morbidity rates}

Neurological morbidity after first surgery was $44 \%$ in our study, which is generally in line with the $33 \%$ and $54 \%$ neurological complications in recent studies [16, 22].

The rates of endocrinological complications after craniotomy vary greatly in the literature. An explanation for these differences can be found in the fact that endocrinological complications are typically reported in series of (supra)sellar tumors. Comparison with these percentages is not reasonable as our study included only a small number of (supra)sellar tumors.

The prospectively established postoperative wound infection rate in the neurosurgical department of the VUmc (adults and children combined) is lower than 5\% (data not shown). The high percentage of $21 \%$ short-term infection after first surgery found in this present retrospective study includes all infectious complications after surgery, not only wound infections. The majority of these were caused by temporary external CSF diversion, which was often complicated by transient meningitis. This warrants further investigation and improvement. The rate of postoperative wound infections in this cohort was less than $2 \%$ (two out of 137) and compares favorably to published rates $[9,21]$.

All temporary and permanent CSF disturbances were registered as surgical complications. A large proportion of the permanent disturbances, however, can be attributed to the nature and location of the brain tumor itself. The rate of long-term shunt dependency in this study was low compared to other surgical series, but comparison is difficult in these mixed case series $[1,21,22]$. A recent study of a mixed cohort (pediatric posterior fossa tumors) of two institutions combined showed a considerable difference ( $31 \%$ vs $19 \%)$ in the rate of permanent CSF diversion at 6 months [15]. 
Fig. 6 Total cumulative survival

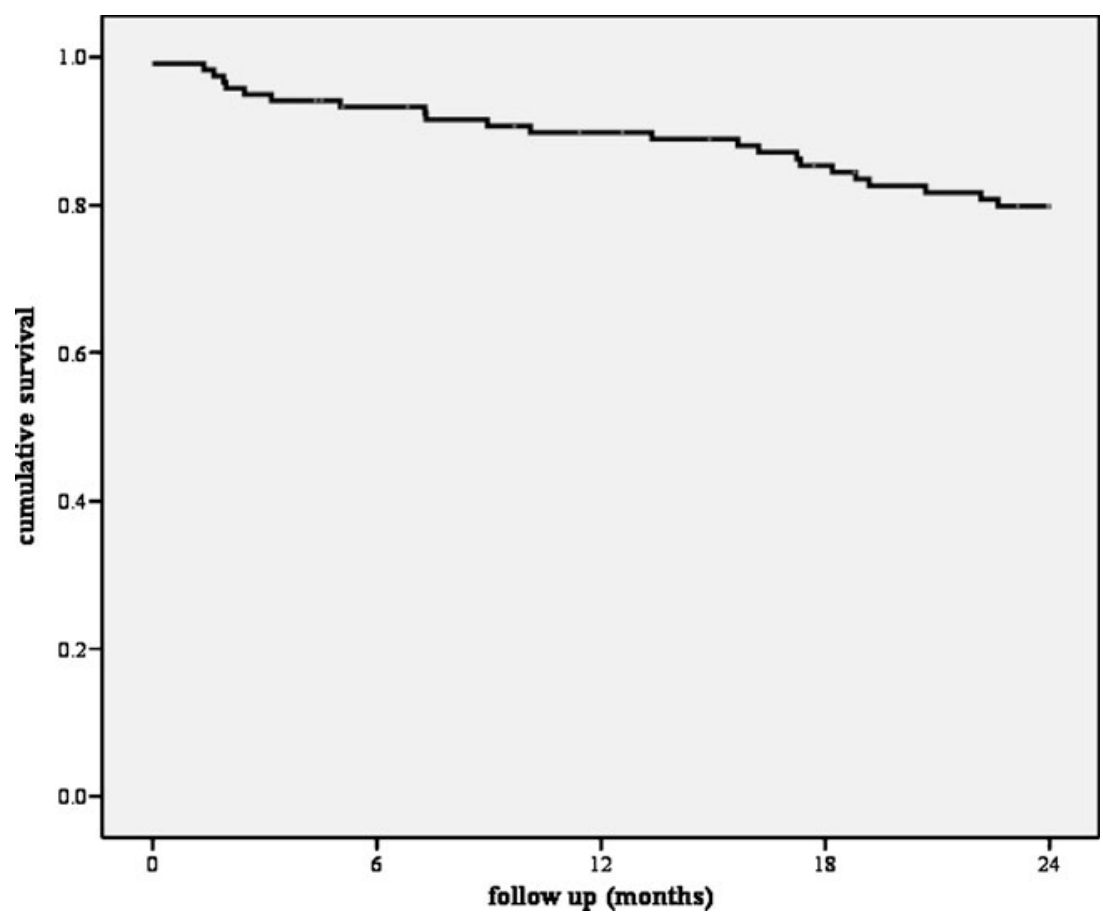

The rates of other complications were all relatively low and comparable with other studies $[1,7,9,16,21]$.

\section{Mortality rates}

In the literature, overall mortality varies from $5 \%$ to $40 \%$ $[9,13,18,22]$. As stated earlier, comparison of series with a different case mix is difficult, as different tumor types will influence overall survival. This is clear when comparing pilocytic astrocytomas with, e.g., brainstem tumors. In addition, the mean age of the studied population in published series also differs considerably.

\section{Literature review}

In the literature, overall surgical morbidity rates vary from $10 \%$ to $54 \%$. The rates highly depend on the nature of the tumors studied, as morbidity for brainstem tumors or optic
Fig. 7 Cumulative survival according to the $\mathrm{WHO}$ classification

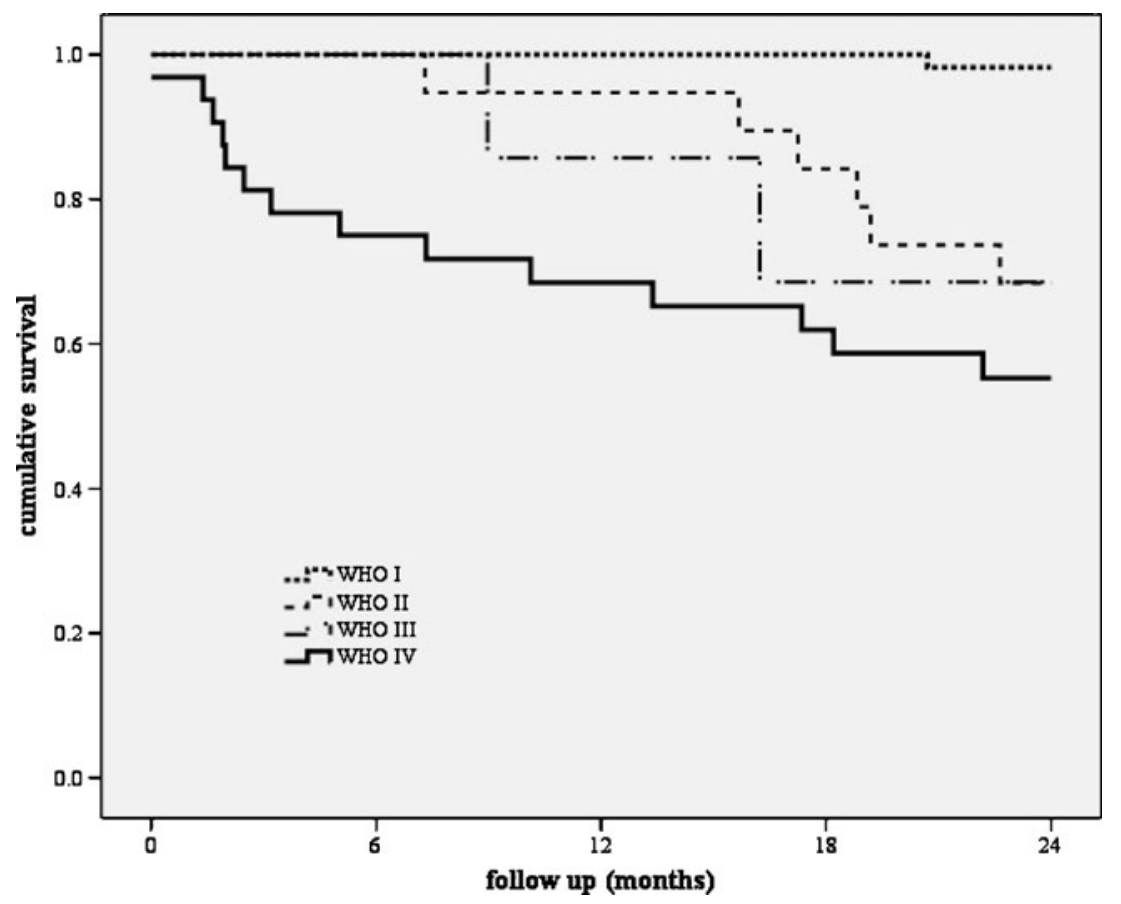


Fig. 8 Cumulative survival of patients according to the extent of tumor resection

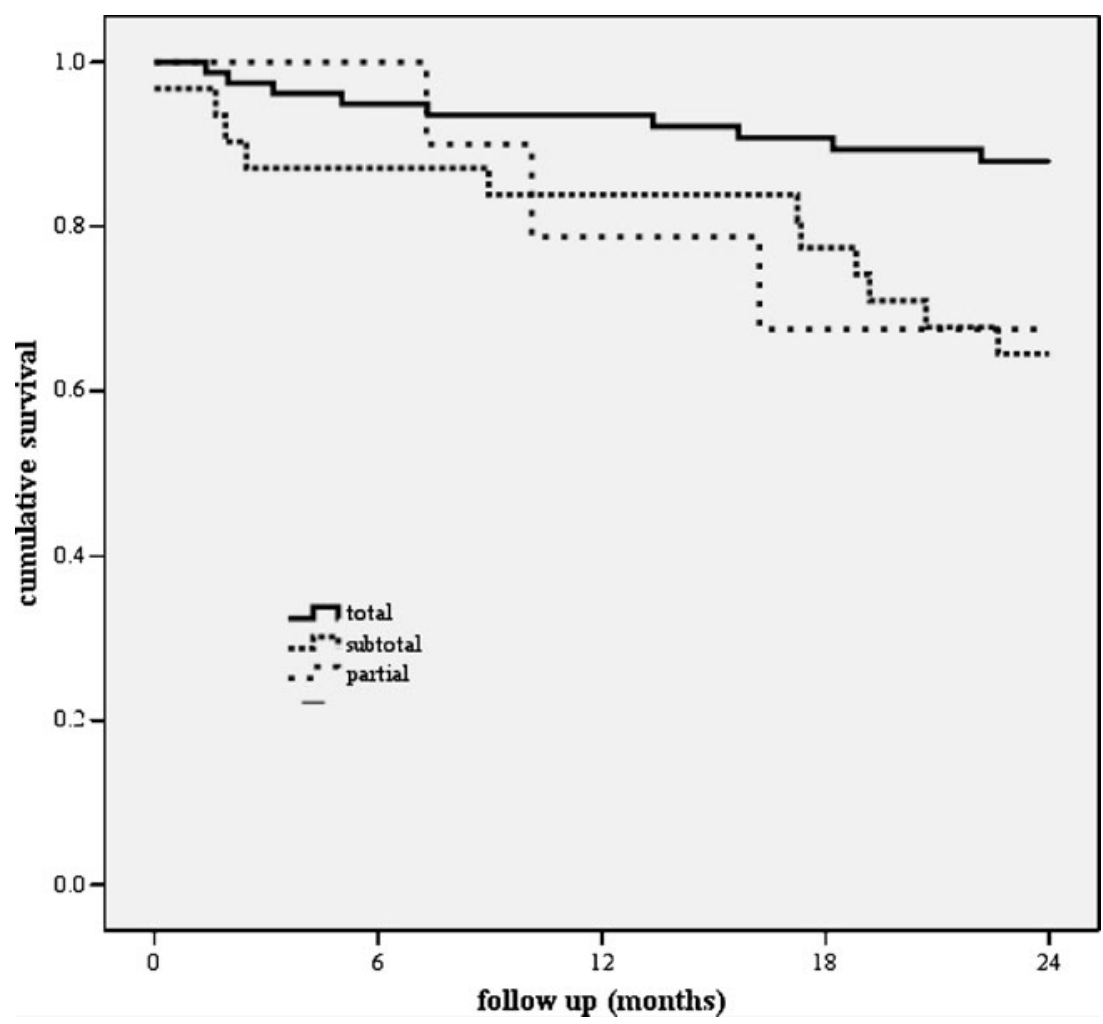

gliomas will obviously be higher than morbidity for hemispherically located tumors $[2,7,16,18,21,22]$.

In addition, the percentages can differ due to different inclusion criteria for different complications. For example, sometimes the natural history of a disease is included as a complication, as our study defined any event that caused postoperative symptoms or led to an unexpected intervention as a complication. In addition, no detailed information about surgical procedures performed in other hospitals was available for the current study. As a result, some of the patients who underwent surgery in our hospital for the first time had been operated earlier in another institution. Obviously, this would have negatively influenced morbidity rates. It is understandable that the overall morbidity rate in the current study differs from other studies due to strict application of our criteria. Nevertheless, we conclude that the overall surgical morbidity rate of $69 \%$ (83 complications in 121 patients) after first surgery and 50\% (seven complications in 14 patients) after second surgery are comparable to other mixed series [7-9, 12, 16, 18].

Surgical mortality rates for brain tumors in patients (0-18 years) also vary greatly and range from $0 \%$ to $20 \%$

Table 5 Operative mortality after surgery of pediatric brain tumors in the literature

\begin{tabular}{|c|c|c|c|c|c|c|c|c|}
\hline Year & Author & $\begin{array}{l}\text { Operated } \\
\text { between years }\end{array}$ & $N$ & $\begin{array}{l}\text { Surgical } \\
\text { mortality (\%) }\end{array}$ & TR $(\%)$ & SR $(\%)$ & PR $(\%)$ & Tumors \\
\hline 1994 & Sinson & 1977-1991 & 10 & 20 & - & - & - & Giant cell astrocytomas \\
\hline 1996 & Dirven & 1969-1990 & 73 & 1 & - & - & - & Pilocytic astrocytomas \\
\hline 1997 & Medlock & 1988-1994 & 20 & 0 & 40 & 45 & 15 & Optic chiasm astrocytomas \\
\hline 2002 & Due-Tonnessen & $1960-2001$ & 110 & 9 & 72 & 28 & - & Astrocytomas \\
\hline 2004 & Gonc & 1969-1999 & 66 & 11 & 31 & 52 & 17 & Craniopharyngioma \\
\hline 2006 & Sandri & $1995-2003$ & 17 & 6 & 24 & 41 & 35 & Focal brainstem \\
\hline 1999 & Albright & 1996-1998 & 100 & 1 & - & - & - & Mixed \\
\hline 2003 & Smith & $1988-2000$ & 4712 & 2 & - & - & - & Mixed \\
\hline 2004 & Akay & $1995-2002$ & 27 & 0 & 59 & 33 & 8 & Mixed \\
\hline 2004 & Young & 1988-1999 & 16 & 7 & 7 & 57 & 36 & Mixed \\
\hline 2009 & Neervoort & 1999-2007 & 121 & 1 & 66 & 26 & 8 & Mixed \\
\hline
\end{tabular}

$T R$ total resection, $S R$ subtotal resection, $P R$ partial resection 
$[1,2,7-9,16,18]$. The largest series by Smith et al. in 4,712 admissions (329 hospitals, 480 identified surgeons) for pediatric brain tumor craniotomy found that the mortality rate was $2.3 \%$ at the lowest-volume-quartile hospitals (four or fewer admissions annually) compared with $1.4 \%$ at the highest-volume-quartile hospitals (more than 20 admissions annually) [19]. The surgical mortality in the current study was $0.8 \%$, which is comparable to the lowest rates reported for highest-quartile hospitals.

\section{Conclusion}

The aim of the study was to perform an internal quality control of the pediatric neurosurgical department of the VUmc (Amsterdam, The Netherlands) and to expose the quality of the surgery by reporting the surgical mortality and morbidity of all children ( $0-18$ years) surgically treated for an intracranial brain tumor from January 1999 to August 2007. The overall surgical morbidity rate was $69 \%$ after first surgery, $50 \%$ after second surgery, and one out of two after third surgery. The surgical mortality rate was $0.8 \%$ with an overall mortality rate of $19 \%$ during long-term follow-up (January 1999-August 2007).

We encourage other neurosurgical centers to collect and analyze their own data. This can serve as a basis for comparison with other pediatric neurosurgical centers and should eventually lead to an improvement of pediatric neurosurgical practice and patient care.

Acknowledgments We gratefully thank Mrs. E.J.G. Bah - de Windt, data manager Neurosurgical Center Amsterdam, for her fine secretarial support; M. Emanuel, data manager Pediatric Oncology/Hematology, for reviewing patient records; and M.S. Neervoort, Attorney-at-law, health care law, for her editorial assistance.

Disclaimer The authors do not report any conflict of interest concerning the materials or methods used in this study or the findings specified in this paper.

Open Access This article is distributed under the terms of the Creative Commons Attribution Noncommercial License which permits any noncommercial use, distribution, and reproduction in any medium, provided the original author(s) and source are credited.

\section{References}

1. Akay KM, Izci Y, Baysefer A, Atabey C, Kismet E, Timurkaynak E (2004) Surgical outcomes of cerebellar tumors in children. Pediatr Neurosurg 40:220-225

2. Albright AL, Pollack IF, Adelson PD, Solot JJ (1999) Outcome data and analysis in pediatric neurosurgery. Neurosurgery 45:101106

3. Albright AL, Wisoff JH, Zeltzer PM, Deutsch M, Finlay J, Hammond D (1989) Current neurosurgical treatment of medullo- blastomas in children. A report from the Children's Cancer Study Group. Pediatr Neurosci 15:276-282

4. Brell M, Ibánez J, Caral L, Ferrer E (2000) Factors influencing surgical complications of intra-axial brain tumors. Acta Neurochir (Wien) 142:739-750

5. Cohen K, Broniscer A, Glod J (2001) Pediatric glial tumors. Curr Treat Options in Oncol 2:529-536

6. Cowan JA Jr, Dimick JB, Leveque JC, Thompson BG, Upchurch GR, Hoff JT (2003) The impact of provider volume on mortality after intracranial tumor resection. Neurosurgery 52:48-54

7. Dirven CMF, Mooij JJA, Molenaar WM (1997) Cerebellar pilocytic astrocytoma: a treatment protocol based upon analysis of 73 cases and a review of the literature. Childs Nerv Syst 13:17-23

8. Due-Tonnessen B, Helseth E, Scheibe D, Skullerud K, Aamondt G, Lundar T (2002) Long-term outcome after resection of benign cerebellar astrocytomas in children and young adults $(0$ 19 years): report of 110 consecutive cases. Pediatr Neurosurg $37: 71-80$

9. Gonc EN, Yordam N, Ozon A, Alikasifoglu A, Kandemir N (2004) Endocrinological outcome of different treatment options in children with craniopharyngioma: a retrospective analysis of 66 cases. Pediatr Neurosurg 40:112-119

10. Kalifa C, Grill J (2005) The therapy of infantile malignant brain tumors: current status? J Neurooncol 75:279-285

11. Louis DN, Ohgaki H, Wiestler OD, Cavenee WK, Burger PC, Jouvet A, Scheithauer BW, Kleihaus P (2007) The 2007 WHO classification of tumours in the central nervous system. Acta Neuropathol 114:97-109

12. Medlock MD, Scott RM (1997) Optic chiasm astrocytomas of childhood. Pediatr Neurosurg 27:129-136

13. Osuka S, Tsuboi K, Takano S, Ishikawa E, Matsushita A, Tokuuye K, Akine Y, Matsumura A (2006) Long-term outcome of patients with intracranial germinoma. J Neurooncol 83:71-79

14. Rickert CH, Paulus W (2001) Epidemiology of central nervous system tumors in childhood and adolescence based on the new WHO classification. Childs Nerv Syst 17:503-511

15. Riva-Cambrin J, Detsky AS, Lamberti-Pasculli M, Sargent MA, Armstrong D, Moineddin R, Cochrane DD, Drake JM (2009) Predicting postresection hydrocephalus in pediatric patients with posterior fossa tumors. J Neurosurg Pediatr 3:378-385

16. Sandri A, Sardi N, Genitori L, Giordano F, Peretta P, Basso ME, Bertin D, Mastrodicasa L, Todisco L, Mussa F, Forni M, Ricardi U, Cordero di Montezemolo L, Madon E (2006) Diffuse and focal brain stem tumors in childhood: prognostic factors and surgical outcome. Childs Nerv Syst 22:1127-1135

17. Shu HKG, Sall WF, Maity A, Tochner ZA, Janss AJ, Belasco JB, Rorke-Adams LB, Phillips PC, Sutton LN, Fisher MJ (2007) Childhood intracranial ependymoma. Cancer 110:432-441

18. Sinson G, Sutton L, Yachnis A, Duhaime A, Schut L (1994) Subependymal giant cell astrocytomas in children. Pediatr Neurosurg 20:233-239

19. Smith E, Butler W, Barker F (2004) Craniotomy for resection of pediatric brain tumors in the United States, 1988 to 2000: effects of provider caseloads and progressive centralization and specialization of care. Neurosurgery 54:553-565

20. Steinbok P, Abdurrazag M (1999) Cerebellar astrocytomas. In: Albright AL, Pollack IF, Adelson PD (eds) Principles and practice in pediatric neurosurgery, 1st edn. Thieme, New York, pp 641-662

21. Wisoff JH, Boyett JM, Berger M, Brandt C, Li H, Yates AJ, McGuire-Cullen P, Turski PA, Sutton LN, Allen JC, Packer RJ, Finlay JL (1998) Current neurosurgical management and the impact of the extent of resection in the treatment of malignant gliomas of childhood: a report of the Children's Cancer Group Trial No CCG-945. J Neurosurg 89:52-59

22. Young HK, Johnston H (2003) Intracranial tumors in infants. J Child Neurol 19:424-430 